\title{
MASCULINIDADE E COLONIALISMO: EM DIREÇÃO AO "HOMEM NOVO" (SUB- SÍDIOS PARA OS ESTUDOS DE GÊNERO E PARA OS ESTUDOS PÓS-COLONIAIS NO CONTEXTO DE LÍNGUA PORTUGUESA)
}

\author{
Mário César Lugarinho \\ (Universidade de São Paulo)
}

\section{RESUMO}

Este estudo pretende ser a introdução a alguns problemas que se constituem contemporaneamente no âmbito dos chamados estudos de gênero na medida em que se observa a constituição de identidades masculinas e de masculinidades nos contextos coloniais. A ênfase tradicionalmente dada à identidade feminina e às suas representações literárias criou o estereótipo do "heteroeurologofalocentrismo" que homogeneiza as identidades masculinas sem observar as contingências históricas e culturais que as pluralizam em várias possibilidades. A atenção ao conceito de "homem novo", modelo tanto requerido pelo Estado Novo português, quanto pelos movimentos de independência dos Países Africanos de Língua Portuguesa, demonstra que na busca pela hegemonia bélica concorriam também ideais de masculinidade, muitas vezes afastados das supostas tradições de cada lado.

PALAVRAS-CHAVE: colonialismo, masculinidades, modernidade.

\begin{abstract}
This study aims at introducing a number of problems found in contemporary gender studies when it comes to the observation of the constitution of male identities and masculinities within colonial contexts. The emphasis traditionally given to the female identity along with its literary representations has created a "heteroeurologofalocentric" stereotype that homogenizes male identities disregarding historical and cultural contingences which make them plural. The attention to the concept of "new man", a model required both by the Portuguese Estado Novo as by the groups who constituted the independence movements of the Portuguese-Speaking African Countries, shows that in the quest for victory ideals of masculinity, which were often away from the traditions of each alleged side, also competed.
\end{abstract}

KEYWORDS: colonialism, masculinities, modernity. 
O desenvolvimento dos estudos sobre as literaturas de língua portuguesa, no contexto contemporâneo em que pesam os estudos pós-coloniais, não pode mais abrir mão de uma reflexão mais atenta a partir da história da cultura que envolve a formação do império colonial português em seus diversos momentos que se sobrepõem, tanto na metrópole, quanto nas colônias, do Brasil a Timor. Dessa maneira, o estudo isolado, com um fim em si mesmo, buscando apenas a descrição formal desta ou daquela obra, sem atentar como as obras literárias questionam o seu tempo e sobre a História projetam os seus questionamentos, não é propósito deste artigo. Nosso propósito é fornecer subsídios aos que se dedicam aos estudos da literatura e da cultura no amplo campo projetado pelos estudos pós-coloniais.

A investigação acerca do(s) modelo(s) de masculinidades(s) se revela como subsídio para a compreensão das Literaturas em Língua Portuguesa, nos contextos coloniais, como discurso portador de sentidos heterogêneos e conflitantes na medida em que tanto contradiz, confirma, supera e reinstala a ordem do discurso (FOUCAULT, 1998) e, por conseguinte, a ordem de gênero (CONNELL, 1995).

\section{MASCULINIDADE E NACIONALISMO}

É quase unânime, entre os estudiosos das masculinidades, a afirmação de que os paradigmas identitários que formam o homem moderno podem ser resumidos pela substituição de uma lógica bélica por uma lógica capitalista. No entanto, o processo é efetivamente mais complexo e menos esquemático porque envolve a modificação de padrões comportamentais e culturais que estiveram incrustados por séculos na cultura ocidental.

A lógica bélica que constituía as identidades masculinas não apenas se concretizava pela proteção ao grupo familiar e pela defesa dos interesses da coletividade, mais tarde alargada pela fidelidade a um soberano. Individualmente, ela também se expressava pela defesa da honra masculina, conceito bastante instável, mas que pode ser compreendido pelo grau de comprometimento do indivíduo com algum ideal promovido pela sociedade em que se situa. Daí, a honra ser virtude e considerada, durante a Idade Média, nas ordens equestres, como a submissão e a fidelidade ao soberano, ao mesmo tempo em que essa mesma honra estava comprometida com a fidelidade a uma dama.

Se recuperarmos a maneira como essa lógica se manifestou na Idade Média, observaremos que, nas novelas de cavalaria ou nas cantigas de amor, a honra regia a própria masculinidade do indivíduo: defendê-la era defender o soberano, por conseguinte, porque a devoção à dama nada mais era do que metonímia do próprio serviço ao rei e, por conseguinte, da própria masculinidade. No entanto, o exemplo literário, representado na literatura medieval, não traduz por completo uma identidade masculina, na medida em que a honra cantada deixa de lado a sua relação direta com o 
uso justificado da força e da violência, que iria chegar ao século XIX através da manutenção da prática do duelo. A autonomia do cavaleiro medieval, em defender a sua honra, foi sendo gradativamente substituída, através da organização dos exércitos nacionais, baseados em rígidas hierarquia e disciplina, ao longo dos séculos XVII e XVIII, por sua submissão à vontade de um Rei e, mais tarde, da nação.

O duelo chegou ao século XIX como prática inaceitável porque dependeria da vontade exclusiva dos indivíduos nele envolvidos; além do que o seu desfecho, a morte de um dos duelistas, escaparia ao ordenamento jurídico dos Estados nacionais. A sobrevivência dessa autonomia masculina, apesar de ser prática larga na aristocracia, atravessava todas as camadas sociais e fronteiras, desde a península ibérica até as estepes russas. Como o direito do pater famílias de dispor da vida da esposa e dos filhos, que sobrevivera desde o Direito Romano, fora transferido para o Estado, ao longo do século XIX, o direito individual à defesa da honra foi devidamente interditado porque liberava a violência a quaisquer indivíduos masculinos. Ao proibir o duelo e conferir-lhe o estatuto de barbárie, o Estado condenava a violência, extraindo-lhe da identidade masculina - e, estatuindo-a como barbárie, classificava-a no âmbito dos comportamentos marginais e socialmente inaceitáveis. A honra, ainda, segundo Joane Nagel (1998), passaria a reger uma relação imediata entre masculinidade e nacionalismo concomitantemente ao desenvolvimento do estado nação.

À identidade moderna masculina, em que pese a polidez e o cavalheirismo, foi atrelado o autocontrole, que se contrapunha ao excesso das paixões, da violência e da crueldade. O homem moderno serviria ao Estado, à família e ao trabalho e não a si mesmo e aos seus interesses particulares. Assim passa ser considerado o novo sentido ao conceito de honra: seu serviço a essas instâncias sociais confere ao indivíduo o reconhecimento coletivo e, quanto menos interesse individual demonstrar, maior será a sua honra e o seu valor. Nos espaços laborais de toda a sorte, a honra deveria estar presente, ressalta-se, na medida em que os atos especulativos deveriam ser reprovados e condenados, bem como a preservação da propriedade e a lógica da acumulação, porque as fortunas deveriam se formar tendo em vista o bem da família e do estado. Na guerra, a honra se comprovava pelo respeito ao inimigo e pela condenação a qualquer forma de humilhação imposta ao derrotado - a vitória seria celebrada não pela fraqueza do oponente, mas pela força do vencedor. Não se deve esquecer que toda essa ética submete-se ao estatuto da nacionalidade: quanto mais honrada for uma nação, mais colherá respeito, autonomia, soberania e deferência frente às outras nações que lhe reconhecerão, naturalmente, a sua superioridade. A honra masculina será, notadamente, a maior expressão da identidade nacional.

George Mosse destaca que esse novo conceito de masculinidade, colado à identidade nacional, tornou-se praticamente invisível para historiadores, antropólogos, psicólogos e cientistas políticos (MOSSE, 2000, p. 7) na medida em que se "naturalizava" nas instituições sociais. A partir 
daí, continua Mosse, a masculinidade e o patriotismo estiveram fortemente associados a tal ponto que:

La construcción de la masculinidad moderna tuvo lugar no sólo dentro de un panorama de sociedad de clase media, sino también en consonancia con el surgimiento de una nueva conciencia nacional. La nación adoptó el ideal de masculinidad como suyo propio: los héroes revolucionarios franceses luchaban para defender La patrie. [...] las más nobles ideas de la virtud masculina son llevadas a la práctica en la guer$\mathrm{ra}$, al igual que se decía que las naciones alcanzaban la grandeza de la que eran capaces solo tras un largo y sangriento conflicto. [...] Sin embargo, siempre era el nacionalismo el que exaltaba el estereotipo masculino como uno de sus medios de autorepresentación. (MOSSE, 2000, p. 64-65).

O trinômio, nacionalidade-masculinidade-heroísmo, é deveras flagrante, porém muitas vezes invisível, na medida em que não são observados os valores do herói nacional (a honra, a bravura, a coragem, o domínio das paixões, a obstinação) como explicitamente masculinos. Construído como estereótipo, o herói nacional é capaz de aglutinar multidões que, ao se identificarem, também se submetem aos valores da mesma nacionalidade. Apesar da alegoria de Marianne demonstrar uma face feminina, a república francesa, sustentara-se sobre os ombros dos soldados do exército nacional, como a indicam os versos de La Marseillaise.

Voltando ao espaço português, o culto prestado pelo estado, nos séculos XIX e XX, a Vasco da Gama e a Afonso de Albuquerque projeta neles os valores requisitados à modernização e passam a representar o necessário ideal regenerador da nação. Quando Eça de Queirós, em A ilustre casa de Ramires, aponta continuamente a África como espaço doador de sentido para a regeneração de Ramires, a (re)construção do império colonial já se constituía como saída para a nação e para seus homens, adoecidos e mergulhados na melancolia.

\section{AS CONTRADIÇÕES DO COLONIALISMO PORTUGUÊS}

Ronaldo Vainfas (VAINFAS, 2010), seguindo Laura de Melo Sousa (SOUSA, 1986), adverte para o fato de o colonialismo ibérico ter se formado concomitantemente às guerras religiosas europeias e à contrarreforma, o que lhe deu um sentido sagrado, semelhante ao das Cruzadas. Ao mesmo tempo, a ocupação do espaço americano e a submissão de suas populações se ofereciam como um empreendimento lucrativo sem precedentes na História. A fé e o lucro estavam reunidos na concepção colonial e viriam a constituir outra forma de dominação.

O colonialismo, de forma geral, apagou as culturas dominadas, submetendo-as ao sistema cultural do dominador. O processo de 
submissão de populações, e aí é englobada tanto a população catequizada (ameríndios), quanto a escravizada (africanos e ameríndios), era baseado numa concepção de humanidade e masculinidade próprias que estabeleciam o homem europeu como superior porque dotado de humanidade e, também, de masculinidade, ${ }^{1}$ enquanto a população submetida, se não era dotada de humanidade, era desprovida de "autêntica" masculinidade e, por isso, considerada feminilizada ou infantilizada, o que justificava a sua submissão. ${ }^{2}$

O europeu, nos espaços coloniais, passou a exercer uma identidade ambígua porque, se por um lado era o conquistador, era também parte constituinte da população sobre quem exerceu domínio. Foram necessárias formas de negociação amplas, em que se cediam pontos para a manutenção da estabilidade colonial. Em vista disso, a constituição das sociedades híbridas na América portuguesa, mas também, e principalmente, na África, foi o índice mais evidente dessa atividade ambígua do colonizador português, já que a sua cultura não foi de forma alguma capaz de manter-lhe afastado e em condição de superioridade frente aos povos dominados.

Reconhece-se que as identidades de gênero, mesmo quando tomadas a partir da constituição do patriarcado ocidental, variam de acordo com as diferenças históricas e geográficas dos povos. O processo de disseminação do patriarcado no ocidente se inscreveu na História como uma longa duração e seu estereótipo mais próximo foi o senhor feudal, que era vassalo de um rei, detentor de extensões territoriais consideráveis e de suas populações (os servos) e, por conseguinte, de mercenários sob seu comando autônomo. Isso torna possível observar uma linha de continuidade, também presidida pela já referida lógica bélica, que une a sociedade feudal e a sociedade colonial, na medida em que foi através da instituição patriarcal que o poder era exercido diretamente, mesmo quando essa instituição já se encontrava em franco processo de superação na Europa.

Gilberto Freyre, em uma de suas inúmeras referências ao patriarcado colonial brasileiro (FREYRE, 1986, p. 53), comenta que foi através de sua instituição que a metrópole pôde exercer o poder de fato sobre o território e sua população - garantindo sua submissão às instituições coloniais e metropolitanas, consequentemente. Freyre, acompanhado por Vainfas (2010), sublinha que a ausência de instituições políticas e sociais, capazes de atingirem todas as distâncias que os territórios coloniais impunham, demandava a experiência cotidiana do patriarcado a fim de que as populações de colonos (brancos, mestiços, ameríndios e escravos africanos) se submetessem ao mesmo poder colonial. No entanto, a instituição do estado nacional e o consequente abandono do patriarcado, durante o século XIX, definiram a emergência da identidade masculina moderna, porque se amalgamava à emergência do estado nacional. Há, aqui, uma ruptura evidente no modelo de masculinidade na medida em que o direito do pater familias se esvaziava e era substituído pelas instituições jurídicas nacionais. 
Durante o processo colonial, o patriarcado, exercendo efetivamente o poder colonial, estabelecia o patriarca, e aqueles que lhe estavam próximos, como detentor do modelo identitário, gerando uma distinção clara com aqueles que a ele se subordinavam. Isto é, a expressão da identidade masculina hegemônica do patriarca definiria as masculinidades não-hegemônicas e, também, as hierarquias a ele subordinadas: mulheres, brancas ou não, crianças e todos os outros exemplos de indivíduos agregados e subordinados à autoridade patriarcal. É dessa maneira que o patriarcal e o colonial se universalizam, destituindo de autonomia quem lhe era exceção ou vivia dele excluído.

A emergência do estado nacional não eliminou o expediente do patriarcado, mesmo quando já se esvaziara da autonomia feudal, substituiu-o pela autoridade masculina, resquício do pater familias, fazendo do patriarca o representante da ordem jurídica do estado. Sua manutenção se deu a partir da definição das rígidas fronteiras que os discursos científicos e filosóficos do século XIX delimitaram.

A superioridade do homem por sobre a mulher e do homem branco europeu por sobre todos os homens não brancos e não europeus ficou garantida, instituindo as exceções a partir de um conjunto de oposições: aqueles que não se colocavam em função do padrão masculino, europeu e branco, eram tratados sob o estatuto da subordinação, infantilizados, feminilizados e/ou marginalizados.

A formação dos estados nacionais europeus se deve à chamada Paz de Westfália, porque criou rígidas fronteiras geográficas entre as monarquias europeias, na medida em que definiu "a localização (externa) da diversidade como uma ameaça, de forma que a diferença era mantida no exterior pela defesa das fronteiras e contida na 'cruzada interna' pela unidade da comunidade política doméstica” (JESUS, 2011, p. 128), o que geraria uma homogeneização cultural no interior das fronteiras dos estados e, por contiguidade, nas colônias dessas mesmas potencias.

Políticas europeias, iniciadas no século XVII, passaram a instituir a homogeneização interna dos estados soberanos, primeiramente através da religião, depois da língua, das etnias e, por fim, das culturas, todas submetidas à clave da nacionalidade. Judeus, protestantes, católicos, ciganos, toda a sorte de diferença poderia ser passível de exclusão. Mas ao ser transposta para o espaço colonial, essas políticas de exclusão dependeriam da instituição patriarcal para se consolidar. Foi preciso, por inúmeras vezes, recorrer à mestiçagem para constituir uma população capaz de ocupar o espaço colonial. Tal recurso já havia sido utilizado, com clara anuência da coroa, e com sucesso, durante a ocupação e povoamento das terras insulares africanas, notadamente os arquipélagos de Cabo Verde e de São Tomé e Príncipe. ${ }^{3}$ Com o surgimento de populações mestiças, foi constituída uma zona fronteiriça na qual o estereótipo da identidade masculina do colonizador se estabeleceu. Nessa zona de 
fronteira era constituída uma identidade que equiparava gênero e etnia, na qual o gênero se destacava como componente principal, sobrepondo-se às noções de raça ou etnia, porque o papel hegemônico mais dependia do exercício da identidade masculina do que de sua ascendência europeia "pura".

Ronaldo Vainfas (2010) e Laura de Melo e Sousa (1986) atentam para o fato de que a ausência de uma sede da Inquisição portuguesa fora da Europa e a pouca disponibilidade de sacerdotes para o exercício efetivo do controle da fé fizeram das colônias portuguesas territórios de liberalidade e promiscuidade. Tais sociedades notabilizaram-se pelo apagamento das fronteiras nítidas entre o que se pudesse apontar como europeu ou não europeu (cf. ALMEIDA, 2004, e GOUVEA, FRASÂO e SANTOS, 2004). Assim, práticas diversas, oriundas das culturas que eram envolvidas pelo colonialismo, passavam a coexistir com algum assentimento das autoridades coloniais. Vainfas, ainda, afirma que o processo de colonização era uma "contradição insolúvel da Reforma Católica no Brasil" porque "fornecia à Igreja a oportunidade de expandir-se no ultramar, ao mesmo tempo em que, operando-se à base da escravidão e da miscigenação cultural, inviabilizava a 'cristianização das massas' levada a efeito na Europa" (VAINFAS, 2010 p. 63). Daí é possível entender como algumas práticas encontravam respaldo em crenças populares como aquela que justificava que "a melhor cura da sífilis consistia na cópula com negrinhas virgens" (FREYRE, 1986, p. 137), crença e prática que ainda permanece no sul da África quando se trata da "cura" da pandemia da AIDS na região (EDINI, 2009).

Como a identidade masculina hegemônica do colonizador encontrava dificuldades de ser desenvolvida nos espaços ocupados, o homem branco acabava por se submeter às práticas sociais e culturais tanto das populações locais, quanto das populações escravizadas, denotando uma evidente modificação na formulação de sua identidade. Aliás, a constituição da masculinidade hegemônica portuguesa já foi bastante problematizada por Miguel Vale de Almeida em sua tese de doutoramento (ALMEIDA, 2000) e também apontado, num outro contexto, por Rui Aragão (ARAGÃO, 1985).

Sobre esse aspecto, é preciso deixar claro que existe uma equação evidente que estabelece uma relação imediata entre masculinidade e colonialismo. Como se sabe, com a independência do Brasil, Portugal atravessou o século XIX como uma nação em quase permanente crise política, social, cultural e, sobretudo, econômica. As sucessivas disputas de poder, os golpes políticos e militares, as revoltas populares e as opções da política interna, no que tangia a uma reforma agrária, educacional e ao desenvolvimento econômico, determinaram um quadro em que, se por um lado havia uma ideologia liberal que apontava as reformas necessárias para o desenvolvimento do capitalismo interno, por outro, havia a hesitação permanente em reformas mais capazes de melhorar a distribuição de renda 
e, por conseguinte, e alavancar o "progresso" (palavra de ordem daquele século). Os historiadores do período são quase unânimes em afirmar que as saídas encontradas pelos sucessivos gabinetes ministeriais e pela população apontaram para o exterior (a imigração, notadamente para o Brasil) e a ocupação e exploração efetiva das colônias africanas (v. ALEXANDRE, 2004; GUIMARÃES, 1983).

Ao mesmo tempo, os governos não deixavam de se esforçar por uma modernização e adequação da sociedade a um modelo mais moderno de estado, seguindo em direção de uma política mais liberal. Assim, em $1^{\circ}$ de julho de 1867, foi publicada a lei que instituiu o Código Civil português no qual eram estabelecidos os direitos e deveres dos cidadãos portugueses e substituía as Ordenações que regularam o país até então. ${ }^{4}$

O código de 1867 seguia a onda que tomara os Estados europeus e americanos daquele tempo, quando se constituíam as novas sociedades urbanizadas e o Estado nacional tomava para si o exercício pleno da Justiça. $\mathrm{O}$ código português e a maioria de seus semelhantes europeus e americanos tiveram como princípio e base legislativa o código francês, editado por Napoleão Bonaparte, em 1804. No código português, além do conjunto de leis que reconhecia os direitos e os deveres civis e organizavam as relações individuais entre portugueses, eram expressos os conceitos fundamentais que norteariam a Justiça e o Direito no reino. A proposta do código, além de criar um conjunto de leis orgânicas, reconhecia, no artigo $9^{\circ}$ da lei que o promulgara, que, ao ser estendido ao Ultramar, deveria ser relativizado frente ao direito consuetudinário.

Segundo Göran Therborn (THERBORN, 2006, p. 63 e ss.), mesmo onde não fosse forma dominante das relações sociais (que envolviam tanto a constituição familiar, quanto a administração de bens e capital), durante o século XIX, o modelo familiar burguês, cujo centro de poder localizava-se no lugar do pai e marido, foi expandido por todo o planeta, de maneira que se pode verificar uma verdadeira revolução global nos costumes. O modelo da família nuclear burguesa não apenas redefiniu leis, mas interferiu diretamente nas formas de comportamento pessoal e relacionamento social em culturas completamente diversas e redesenhou a chamada "ordem de gênero", ${ }^{5}$ numa escala nunca antes alcançada por nenhuma outra intervenção colonial, criando uma continuidade flagrante entre as metrópoles e seus impérios. Deve-se ainda levar em conta que o processo se deu, não apenas pelos efeitos legais e jurídicos das leis que o colonialismo implantava nas colônias, mas também, e principalmente, pelas novas relações de trabalho que substituíam a escravidão por alguma forma de trabalho assalariado.

Em 18 de novembro de 1869, foi editada a lei que estendeu ao Ultramar os efeitos do Código Civil de 1867, ressalvando que nos territórios da Índia, Macau, Timor, Guiné e Moçambique fossem observados 
costumes e tradições locais, que regeriam processos e decisões judiciais entre "gentios". Além disso, a mesma lei deu reconhecimento de matrimonio civil àqueles contraídos por não católicos no Ultramar, reconhecendo-lhes o direito de constituição de família e submissão ao código.

Dessa maneira, o império colonial português não ficou à parte do processo apontado por Therborn (2006), e tratou de levar às populações sob seu domínio o padrão legal e social que suas leis determinavam. Notadamente, esse processo alcançou quase imediatamente as ditas "sociedades crioulas" que se haviam desenvolvido nos domínios portugueses no continente africano, como se verifica pelo caput da lei que estendeu a validade do Código Civil de 1867 ao ultramar, sem ressalvas nos arquipélagos de Cabo Verde e São Tomé e Príncipe e nos territórios da costa ocidental africana. ${ }^{6}$

A instituição dos papéis sociais, agora renovados pelo ideal de bem estar familiar, era reservada tanto a homens quanto a mulheres, porque definia os seus direitos e deveres. É importante ressaltar que a maior parte do código de 1867 se destinava a definir o direito de propriedade, bem como as formas com as quais os indivíduos dela pudessem dispor. Entretanto, o direito do pater familias pouco se modificou, apenas acentuando-lhe as responsabilidades como pai e marido. Na verdade, as modificações mais consideráveis são oriundas do período republicano que, através de decretos publicados imediatamente após a proclamação da república (1910), reconheceu o divórcio e a igualdade de direitos e deveres dos cônjuges no núcleo familiar. Foi quando também foram reconhecidos os direitos da esposa e dos filhos, tendo em vista o seu bem estar à revelia da vontade do marido e do(s) pai(s). Reconhece-se que foram os dispositivos, legais e republicanos, que sepultaram, no âmbito jurídico, todos os resquícios do pater familias. Apesar disso, após a instalação da ditadura, em 1926, e do Estado Novo, em 1933, houve esforços por parte do estado de fortalecer a autoridade masculina no âmbito social e familiar, recriando a mística imperial e o culto aos heróis nacionais, dos quais emanaria a exemplaridade ao novo homem português necessário à reconstrução da Pátria e do Império (v. ALMEIDA, 2004).

\section{O "HOMEM NOVO"}

Se considerarmos a aplicabilidade das leis que buscaram regular a sociedade portuguesa e as sociedades coloniais, observamos que o seu sucesso dependia de ações do Estado e, no caso das colônias, acrescidas de um processo de aculturação e de imposição que viria a modificar o direito consuetudinário e as práticas tradicionais que regulavam as sociedades coloniais. Neste sentido, foi com essa evidente perspectiva que o Estado Novo forjou, a partir das teorias que circulavam pela Europa, principalmente nos regimes totalitários da Alemanha nazista e da Itália fascista, mas também da União Soviética, o conceito de "homem 
novo", 7 sujeito de uma "portugalidade". ${ }^{8}$ A pátria, a família e a religião seriam tratadas como uma tríade indispensável para a efetiva execução do ambicioso projeto nacional do Estado Novo, compreendendo-se que nesse projeto eram também englobados os territórios coloniais.

O conceito de "homem novo" compareceu, no contexto histórico do Estado Novo, inicialmente, num discurso de António de Oliveira Salazar, quando da comemoração do décimo aniversário da instalação da Ditadura Militar (28 de Maio de 1936, em Braga), e ficou conhecido como o "discurso de Braga" ou o "discurso do $10^{\circ}$ ano". Nesse famoso discurso, foram salientadas as diretrizes de uma política efetiva de reeducação e de regeneração coletiva e individual que visava à constituição do "homem novo" português, a quem caberia ao estado moldar, capacitando-o a cumprir e interpretar a alma e o destino ontológico da nação que o antecedia e se lhe sobrepunha, vinculando-lhe atitudes, pensamentos e modos de vida, redefinindo e subordinando o particular ao império do "interesse nacional" (cf. ROSAS, 2001, p. 1035-1036).

\section{O historiador Fernando Rosas destaca ainda que:}

Não só, nem principalmente, como sujeição do individual ao colectivo, mas como padronização tendencial dos espíritos e dos "modos de estar" de acordo com os "valores portugueses" de sempre, que o regime definia, representava e tinha como missão fazer aplicar. Esse ser renovado, expurgado dos vícios do liberalismo, do racionalismo e da contaminação marxista, esse ser reintegrado, por ação tutelar e condutora do Estado, no verdadeiro "espírito da Nação", haveria de ser temente a Deus, respeitador da ordem estabelecida e das hierarquias sociais e políticas como decorrências do organicismo natural e imutável das sociedades, pronto a servir a pátria e o império, cumpridor dos seus deveres na família e no trabalho, destituído de "ambições doentias" e "antinaturais" e satisfeito com a sua honrada modéstia. (ROSAS 2001, p. 1037)

Assim como acontecera na Alemanha antes da ascensão do nazismo, Portugal, durante os anos anteriores à primeira república (1910-1926), experimentara uma turbulenta fase política, na qual se destacou uma intensa produção cultural. Daqueles anos, o maior destaque é dado ao aparecimento da revista Orpheu (1915) e, consequentemente, ao desenvolvimento das experimentações modernistas. Vale assinalar que, segundo Rui Ramos (1994), durante esse período não apenas o modernismo floresceu, mas também um feminismo mais politizado com uma pequena, porém ousada, emancipação, apesar disso. "A imprensa festejava as pioneiras, porém nunca deixava de gozar o feminismo sufragista” (RAMOS, 1994, p. 638).

A ausência de censura oficial há mais de um século beneficiara os modernistas portugueses, cujo público tinha acesso garantido a uma produção que, em muitos países europeus, encontrava-se proibida, como 
D. H. Lawrence, Henry James ou James Joyce. A considerada liberalidade da produção cultural portuguesa devia, ainda, a alguns autores, como Abel Botelho, Alfredo Gállis, o Visconde de Villanova, ou Teixeira Gomes, que possibilitaram a constituição de um público leitor menos escandalizado com propostas consideradas ousadas para a moral mais conservadora dominante. Contudo, em 1923, as Canções, de António Botto, os poemas de Judith Teixeira e a ousada produção de Raul Leal foram alvos de censura e de escândalo público, levando a uma "cruzada" pela moralidade, tendo à frente a Liga de Ação dos Estudantes de Lisboa, que passou a exigir a censura prévia à circulação de livros (LUGARINHO, 2003).

A partir daí, ainda segundo Ramos, houve margem para a criação, na esteira das condições políticas e culturais da Europa daqueles anos, de um ambiente de polarização radical entre formas de compreensão da vida social e individual (RAMOS, 1994, p. 660). Ramos propõe que esse confronto se dava a partir de uma visão plural e outra totalitária de compreensão da vida coletiva e individual. Ou seja, se, por um lado, modernistas punham em cena não apenas temas considerados tabus, propondo a constituição de uma experiência plural de sociedade, na qual os anseios individuais se conformariam criando uma pluralidade de comportamentos e identidades que sepultariam os estereótipos sociais, por outro, um movimento contrário, também ancorado em propostas constituídas durante o século XIX, propunha a construção de uma sociedade nova, baseada em valores coletivos, dos quais o nacionalismo, o eugenismo e a preservação da religião e da família seriam facilmente destacados. A profusão de ideais e ideias levava a uma instabilidade ideológica, potencializada a partir do fim da I Grande Guerra (1915-1918), e viria a fomentar os caminhos políticos tomados pela Itália, Alemanha, Espanha e Portugal e com forte interferência na nascente União Soviética. Essas nações, no período entre guerras, experimentaram, em maior ou menor grau, períodos de instabilidade institucional, a que se seguiram regimes de força, com estados centralizadores, nos quais uma ordem juridicamente organizada passava a impor uma padronização identitária evidente (cujo paroxismo foi o arianismo nazista). É desse período que surgem os vários discursos que irão emergir em Braga, na medida em que o Estado Novo português chamava para si a tarefa de regeneração nacional. ${ }^{9}$

O processo de regeneração, como informa Rosas, seguindo José Ramos do Ó (1992), seria efetivado através da instituição de um programa nacional de educação, aliado ao amplo conjunto de instituições que o estado criara (como a "Mocidade Portuguesa") e à propaganda do estado, emanada pelo Secretariado de Propaganda Nacional (SPN), dirigido por António Ferro. A "portugalidade", virtude almejada pelo "homem novo", não se resumia apenas à submissão do homem português às razões do estado, mas a sua crença inquestionável nessas razões e a sua inserção num modo de ser (num "hábito" cujo fim seria a estabilidade do estado e, por conseguinte, da 
sociedade), a manutenção e propagação da "civilização portuguesa" (onde se incluía a fé católica, os valores da ruralidade, pobreza e o culto do passado e dos heróis nacionais). E, ainda no investimento permanente na "mística imperial" (finalidade mais ambiciosa que pretendia inserir o homem português no projeto colonial do Estado Novo, criando-lhe uma sensação de territorialidade alargada, aliada a "sua" missão civilizadora). Ressalta-se que o conceito de "regeneração" comparece de maneira superada, sendo convertido em (re)educação - passava-se do hospital à escola, da doença à ignorância, da profilaxia à pedagogia. No entanto, a atividade de reeducação manteve os seus protocolos cirúrgicos porque cabia ao estado extirpar os organismos sociais adoecidos ou mortos, através da sua política de segurança, consubstanciada pela instituição da Polícia de Vigilância e de Defesa do Estado - PVDE, 1933 - e, na década seguinte, pela Polícia de Investigação e Defesa do Estado - PIDE, 1945 (cf. TORGAL, 2009, p. 398-422).

A opção demasiadamente óbvia do Estado Novo pela criação do "homem novo" se opunha ao homem urbano, cosmopolita, hedonista e libertino, porém decadente, que se engendrara na cultura europeia do fin-de-siècle. Essa imagem de homem adentrara o século XX, resistira aos ímpetos revolucionários e à I Grande Guerra, tornando-se o padrão modernista que, bem mais tarde, viria a reflorescer nos Estados Unidos da geração beatnik e no movimento da contracultura (cf. EKSTEINS, 1991; BODY-GENDROT \& ORFALY, 1992; RAMOS, 1993). Em Portugal, seria o movimento surrealista que se oporia de maneira radical a essa proposição, já que, como indica Vale de Almeida (2004), o próprio movimento neorrealista era devedor da perspectiva estadonovista na medida em que:

Até o internacionalismo marxista se nacionalizaria, transformando-se em populismo graças às obras artísticas do neorrealismo, em que uma imagem mais convincente de "povo português" cumpriu uma assimilação dos poderes do patriotismo, tendo mesmo reforçado a imagem idealizante de Portugal. As únicas contra-imagens a isto vieram do movimento surrealista nos finais da década de quarenta. (ALMEIDA, 1997, p. 61)

A derivação do conceito desse homem moderno, que se estende desde o fim do século XIX até os estertores da contracultura na década de 1960, não é uma verificação apressada, e sim resultado da observação dos valores plurais que as culturas das nações vitoriosas em ambas as guerras viriam a disseminar. ${ }^{10}$

Assim como a família burguesa e os papéis sociais que no seu interior eram desempenhados por homens e mulheres, uma reação direta a essa ordem de estado se disseminava nos ambientes de produção artística e literária dos anos finais do mesmo século XIX e seguiria por toda a produção do século XX, indo atingir as mais variadas formas de manifestação artística. Havemos de, no entanto, sublinhar que essa reação chegou a possuir 
um forte cunho individualista e hedonista, desprezando ostensivamente os valores burgueses e nacionalistas. Esse outro padrão de masculinidade encontra nos modelos do flanêur e do dândi, alguns de seus suportes mais conhecidos, e não é de se estranhar que aqui haja uma contradição entre os modelos verificados.

Se retornarmos ao momento de ruptura com o Antigo Regime e ao consequente desenvolvimento dos estados nacionais europeus, verificaremos que havia um modelo de masculinidade que emergia, identificado pelos valores que garantiriam a estabilidade da sociedade burguesa: a nação, a família e a propriedade. Sem dúvidas, esse foi o modelo mais atualizado do antigo patriarcado e que sobreviveria no discurso estadonovista, mesmo quando já esvaziado do reconhecido direito do pater familias. Ao mesmo tempo, outros modelos marginais, a que já nos referimos, e que não se adequavam imediatamente à homogeneização social pretendida pelo estado nacional, passaram não apenas a ser objetos de atenção da produção artística e literária, mas se constituíam como sujeitos e protagonistas dessa mesma produção: o flanêur, o dândi, o viajante, o aventureiro. Walter Benjamin (1987), por exemplo, por diversas vezes apontou esses personagens contraditórios à cidade moderna, palco reconhecidamente privilegiado da sociedade burguesa, como aqueles que punham em discussão os modelos homogêneos daquela mesma sociedade. Na mesma direção, e perseguindo a lógica benjaminiana, Marshall Berman (1987) observou que a personagem Fausto, da tragédia homônima de Goethe, em sua última versão (1832), era a expressão mais bem acabada do homem moderno, na medida em que aliava as virtudes burguesas, a submissão ao Estado e a confiança absoluta na ciência instrumentalizada, em favor de um bem-estar coletivo que não levava em consideração os indivíduos e seus interesses particulares. Para Berman, ainda seguindo Benjamin, o aparecimento da poesia de Baudelaire teria sido o primeiro discurso de reação à emergência da vida e do homem modernos. Assim, esses personagens marginais, que, ironicamente, foram eleitos para representarem no cânone literário o melhor da produção do século XIX, produziram sentido às gerações posteriores, decididamente de poetas e artistas da mais variada ordem. George Mosse (2000) lembra que essas formulações variantes à identidade hegemônica seriam as antíteses necessárias ao modelo para que esse mesmo modelo fosse reconhecido como válido e incontestável (MOSSE, 2000, p. 92).

Os modelos não hegemônicos de masculinidade, apesar de desprezados socialmente e objetos de investigação científica, ${ }^{11}$ eram privilegiados pela Arte que, numa perspectiva nietzschiana, seria a resistência possível à homogeneização que a Ciência e, acrescentamos, o estado nacional levavam a cabo naquele século. $\mathrm{O}$ movimento da arte moderna, que reúne os "modernismos", seria depositário de ambos os discursos, tanto o celebrativo, como em Marinetti, no futurismo italiano, e, posteriormente, Antonio Ferro, na arte do estado novo português, quanto nas figuras mais controvertidas, cujas obras expressavam as aporias daque- 
les tempos, como as de Fernando Pessoa, Ezra Pound, Maiakovsky, ou, naqueles cuja marginalização seria mais evidente, como em Frederico Garcia Llorca, Mário de Sá-Carneiro ou Walt Whitman.

Essas perspectivas vieram a se entrelaçar com os projetos políticos que se desenvolviam durante as duas primeiras décadas do século XX. Vale assinalar que a perspectiva mais plural e crítica, portanto, aproximou-se, em vários momentos, das perspectivas ditas da esquerda, mas, pelo caráter cada vez mais centralizador dos movimentos comunistas, dela se afastou e foi afastada, também, porque colocava em causa a nova ordem que emergia na sociedade soviética de então. Os regimes de força, tanto à direita, identificados ou não com a burguesia nacional, quanto à esquerda, na efetivação de seus objetivos regeneradores e reformadores, também se ocuparam de colocar à margem os indivíduos que não se adequassem ao pretendido modelo hegemônico.

George Mosse, no entanto, aponta que, entre os modelos propostos nesse tempo, emergira uma formulação de identidade masculina, sob um ponto de vista que abolia tanto a lógica guerreira, quanto burguesa para a sua conformação. O ideal socialista do "homem novo" tornava-se contraponto à masculinidade moderna, já que vinha a se basear na solidariedade, na renúncia à força e na renúncia ao nacionalismo. $\mathrm{O}$ "homem novo" tornar-se-ia realidade a partir do momento em que estaria desvinculado de qualquer traço burguês: "solo una comunidad socialista podía producir una masculinidad nueva y radicalmente cambiada” (MOSSE. 2000, p. 141). O estado soviético propôs um conceito de "homem novo" que viria a se contrapor aos discursos mais bem acabados dos regimes totalitários do Ocidente, com o evidente destaque já dado à versão portuguesa. O conceito soviético fomentaria o conceito de "homem novo" que os movimentos de independência das então colônias portuguesas na África viriam a constituir, fosse durante o período das lutas de libertação, fosse posteriormente às independências dessas nações.

Um artigo, publicado pelo periódico "Problemas - Revista Mensal de Cultura Política”, do Partido Comunista do Brasil, em 1949, assinado por V. Kolbanoski e que teve grande circulação internacional, ${ }^{12}$ apresenta de maneira clara o conceito de "homem novo", tal qual o Partido Comunista da URSS o definira nos anos imediatamente posteriores à II Grande Guerra. Kolbanoski apropria-se do conceito de "homem novo" soviético, a partir de um discurso de Lênin, de 1923, tendo em vista a concepção de moral comunista e o seu compromisso de organização e consolidação do estado soviético, afirmando que:

O Partido Comunista, apoiando-se no conhecimento das leis da edificação do comunismo, define claramente as tarefas que deve cumprir para ensinar a moral comunista e formar o homem novo. [...] $\mathrm{Na}$ sociedade socialista, o bem pessoal de cada um dos membros da sociedade é inseparável do bem geral de 
todos, o bem geral das classes trabalhadoras e de todo o povo soviético. Este caráter inseparável do interesse pessoal e do interesse social, além de estender-se a todas as esferas da vida e da atividade do homem, distingue-se pela sua continuidade. (KOLBANOSKI, 1947, grifo nosso)

Aqui se enquadra uma perspectiva bem diferenciada daquela que era evidenciada pelo Estado Novo, na qual os interesses do Estado estavam travestidos nos interesses da nação, a quem o indivíduo servia. O "homem novo" soviético, tal qual definido pelo PCURSS e apresentado por Kolbanoski, compreende que a coletividade, mesmo convertida numa nacionalidade, se sobrepunha aos interesses individuais (característico das sociedades divididas em classes) e que a solidariedade, emanada pelo trabalho, definiria as relações entre os indivíduos e desses com a sociedade. Não importa aqui os sentidos que "coletividade", "nacionalidade" e "solidariedade" assumem na vida política cotidiana soviética, já que todos podem ser observados como conceitos construídos em função do estado, mas importa o sentido proposto pelo discurso ao ser disseminado entre outros povos - a moral comunista se contrapunha veementemente à moral burguesa.

Os movimentos que se contrapuseram ao processo de disseminação da "portugalidade" e do "homem novo" português, se, por um lado, se aproximaram bastante do discurso soviético, por outro, tiveram formas e manifestações particulares na medida em que em cada território haveria a demanda por uma nacionalidade que se contrapunha à "portugalidade" hegemônica do "homem novo" português. Assim, a "cabo-verdianidade", a "angolanidade" e a "moçambicanidade", cada uma ao seu turno, reivindicaram o seu específico "homem novo".

A apreciação dessa discussão não é simples e requer uma mais aprofundada revisão na medida em que o conceito de "homem novo" está revestido não apenas por formações discursivas do Estado Novo e das diretrizes internacionais do PCURSS e dos movimentos de independência, mas também foram revestidas por formações discursivas de fundo antropológico, histórico e, inclusive, literário. Se o conceito de "homem novo" do Estado Novo está intimamente relacionado ao conceito de "portugalidade", é preciso que tenhamos claro que essa formação discursiva se constitui entre os fluxos e os refluxos dos discursos ancorados aos conceitos de nação e nacionalidade que circulavam no Ocidente. É sabido que o primeiro grupo de intelectuais a oferecer um conceito, sistematicamente construído, que se revelou como diferencial ao discurso da "portugalidade" é aquele que se constitui em torno da revista Claridade, ainda nos anos de 1930, no arquipélago de Cabo Verde.

No entanto, antes de seguirmos, cabem mais algumas considerações a respeito do processo de constituição dos discursos referentes às identidades nacionais produzidos, ainda, durante o século XIX. A cientista política Monserrat Guibernau (1997), professora da Universidade de 
Oxford, chamou a atenção para o fato de que há convergências entre discursos de origem conceitual diferentes, no que tange à análise das identidades nacionais, e que se sobrepõem na medida em que essas identidades os convocam de maneira equilibrada de acordo com suas conveniências. Assim, segundo Guibernau, os discursos a respeito das identidades nacionais, primeiramente nos países europeus, estruturaram politicamente os estados, apesar da ocorrência do conceito de povo-nação poder ser observada anteriormente. Montserrat Guibernau assinala duas linhas de reflexão para essa discussão: uma de forte inspiração "essencialista", na qual o pensamento do filósofo romântico Herder pode ser destacado, porque estabelece uma continuidade entre a nacionalidade, a natureza e a vontade divina, remetendo as relações de parentesco a uma espacialidade e a uma temporalidade comuns aos indivíduos - constituindo uma "origem comum"; a outra, calcada nas perspectivas mais contemporâneas, nas quais a nação e a identidade nacional são construções culturais que estabelecem vínculos de solidariedade entre indivíduos de uma mesma comunidade, compartilhando, com isso, experiências comuns - é a perspectiva da qual a contribuição de Benedict Anderson seria a mais difundida. Para Guibernau, entretanto, quando tomadas de maneira radical

ambas as perspectivas apresentam impropriedades. As baseadas na "naturalidade" das nações simplificam o conceito, incluindo todos os tipos de grupamentos humanos na categoria de nações que remontam a períodos anteriores. As teorias que defendem a modernidade da nação e do nacionalismo ignoram as raízes históricas das comunidades étnicas que se transformaram em nações e mais tarde puderam ou não se converter em estados nacionais. (GUIBERNAU, 1997, p. 58)

Com isso, podemos avançar, com a certeza de que as nações não são fenômenos unicamente modernos, mas são resultantes do desenvolvimento da relação entre o poder do Estado constituído e a soberania popular, sobre a qual recai, posteriormente, o conceito de cidadania. Guibernau ressalta, ainda, que os nacionalismos surgidos em torno da queda do Antigo Regime apresentavam dois vetores de orientação a partir da forma como compreendiam a nação. O primeiro, constituído ao longo da Revolução Francesa, projetava princípios universais, como a igualdade entre os homens, detendo-se, entretanto, na soberania popular, voltado à constituição e ao reconhecimento do Estado como expressão e materialização desse poder. O segundo vetor é o que teria no nacionalismo de cariz romântico a sua base ideológica, visto que tomaria a cultura, não o estado, como ponto de partida (cf. GUIBERNAU, 1997 , p. 65) - buscaria os mitos de origem em raízes culturais comuns como línguas, costumes, passado etc, e se organizaria, sobretudo, como uma reação à homogeneização cultural, baseada em elementos de origens ditas universais. ${ }^{13}$ A produção literária, ao se ocupar da fundação dos discursos formadores da nação, oscilou entre esses dois vetores. 
Salta à vista que ambos os vetores se configurem a partir de uma ordem cultural, já que buscam imaginariamente, por um lado, criar discursos que estabilizem a constituição do estado nacional, ao mesmo tempo em que vinculam, em comunidades, os indivíduos, especialmente através da sensação de pertencimento a uma ordem espaço-temporal que lhes oferece uma origem comum, o que se converte em "mitos de origem". O sentido gerado, a partir do enlace das instituições políticas com os mitos de origem, passa, assim, a dar a sustentação ideológica, imaginária, portanto, ao estado nação. Daí se compreender toda a insistência na reeducação do indivíduo, o investimento no "homem novo" e no imaginário imperial, por parte do Estado Novo português, que não abria mão tanto da reconfiguração institucional como a sua refundação imaginária que, inclusive, prescindia de um "homem novo" capaz de interpretá-la.

Será diante dessas articulações que os discursos nacionalistas dos territórios coloniais irão, cada um ao seu tempo e modo, operar a desarticulação dos mitos portugueses de origem, dados pelas narrativas dos Descobrimentos, e das instituições, reconfiguradas pelo Estado Novo, quando da formalização do Império Colonial. ${ }^{14}$

Em artigo intitulado "O projecto crioulo: Cabo Verde, colonialismo e crioulidade” (2004), o antropólogo Miguel Vale de Almeida observa as linhas mestras que sustentavam a discussão em torno da nacionalidade e identidade dos povos colonizados por Portugal, com ênfase na população do arquipélago de Cabo Verde. A partir da publicação, em 1957, de dois trabalhos, em edição da Junta de Investigações do Ultramar, intitulados "Seroantropologia das Ilhas de Cabo Verde" e "Mesa Redonda sobre o Homem Cabo-Verdiano", ambos organizados por Almerindo Lessa e Jacques Ruffié, Vale de Almeida observa que a crioulidade do homem cabo-verdiano se submete ao conceito de nacionalidade, seja quando levadas em consideração as perspectivas do lusotropicalismo apropriadas pelo Estado Novo, seja quando é enfatizada a tese da identidade autônoma, apontada por Baltasar Lopes. Desse processo, segundo Vale de Almeida, resulta um discurso identitário, apontando para a tese de Guibernau ("o mito das origens", de Herder, associado à construção da comunidade imaginada de Anderson). Isto é, a perspectiva luso-tropicalista e a tese da identidade autônoma são formulações reconhecidamente construídas com finalidades políticas imediatas, como a emancipação através da independência ou a elevação das elites locais a categorias civis mais privilegiadas, tendo como pano de fundo a política assimilacionista implementada pelo Estatuto do Indígena (1954). A perspectiva de Almeida será o ponto do qual partiremos para a verificação dos discursos acerca do "homem novo", como são observados em Cabo Verde e na Guiné, através do discurso de Amílcar Cabral, líder do Partido Africano para a Independência da Guiné e Cabo Verde (PAIGC); em Angola, através da emergência do conceito em discursos do Movimento Popular para a Libertação de Angola (MPLA); e, em Moçambique, através do relato das ações da Frente de Libertação de Moçambique (FRELIMO). ${ }^{15}$ 
Por ter sido o primeiro momento em que a discussão em torno da nacionalidade dos povos colonizados por Portugal e que habitavam o continente africano foi sistematizada, o conhecido movimento de escritores cabo-verdianos que fundaram a revista Claridade ganha relevo - não apenas por sua anterioridade, mas por todos os discursos que nas páginas do periódico se engendraram e por todos aqueles que nele foram envolvidos. Tendo partido da aproximação com a cultura brasileira, os intelectuais cabo-verdianos definiram a mestiçagem como instrumento capaz de aliviar tensões internas, ao mesmo tempo em que integrava a população a modelos exteriores, dentre os quais o português que, se não era excluído, tinha a sua importância diminuída, ao mesmo tempo em que a Antropologia superava a equação entre raça e cultura.

Em consonância com Gabriel Mariano (1991) e Gomes dos Anjos (1998), Vale de Almeida (2004) aponta para o fato de que, até a primeira metade do século XX, o mestiço cabo-verdiano foi privilegiado pela administração colonial, na medida em que ocupava posição destacada na constituição do império colonial, ocupando lugar de mediação com as diversas populações dos territórios colonizados. Em vista disso, Cabo Verde se convertia em modelo para os demais povos africanos colonizados pelo português. Na altura da reunião analisada por Vale de Almeida, quase imediatamente após a publicação do Estatuto do Indígena (1954), o que ficava evidente, ao requererem o estatuto da mestiçagem, era o reconhecimento do cabo-verdiano na categoria de assimilado.

A exposição da importância do tema da assimilação, na perspectiva de Vale de Almeida, permite que se lance um olhar menos ingênuo sobre a forma como o PAIGC e os discursos de Amílcar Cabral viriam a contornar o conceito de "homem novo". Se considerarmos a centralidade dos discursos dos líderes dos movimentos de independência africana no que tange às formas de constituição de políticas efetivas, tanto durante o período de luta armada, quanto no período posterior às independências, na medida em que essas políticas se pautavam pela instituição de modelos sociais, o "homem novo" de Amílcar Cabral possui contornos muito mais amplos do que aqueles propugnados pelo PCURSS. Inspirado pela Revolução Cubana, Cabral (s/d) observa que esse "homem novo" é plenamente consciente dos seus direitos e deveres nacionais, continentais e internacionais - o que o desvincula de sua submissão estreita à nacionalidade, convertendo-o em um cidadão, pleno de direitos e deveres, que reconhece a sua temporalidade e sua espacialidade de maneira alargada. Ou seja, a submissão desse homem ao estado não é condição para o seu reconhecimento, mas para que se atinja esse estatuto é preciso que se faça uma profunda reforma cultural. Para Cabral, essa reforma se constituía pela luta contra as mazelas da tradição (a gerontocracia, o nepotismo, a inferioridade social da mulher), o que o insere numa perspectiva mais "modernista", mas o atrela ao homem do PCURSS na medida em que o sentimento de solidariedade nacional deve reger-lhe as ações. 
No entanto, o "homem novo" se insere numa construção cultural que organiza e dá sentido às tradições do passado, cujas virtudes devem ser aproveitadas, e à contribuição do colonizador e da cultura moderna, a partir da qual se alavanca o desenvolvimento social e econômico da nação. Cabral parece, aqui, estar em consonância com discursos mais contemporâneos, afastados dos vícios da tecnocracia, na medida em que dá relevo flagrante à cultura - o "homem novo" cabralino seria, enfim, uma revisão do "homem moderno", destituído do hedonismo decadentista, colocado em função da nacionalidade - elemento indispensável às lutas de independência e à implementação do estado. Curiosamente, podemos observar que "homem novo" é síntese cultural contraposta à ideia de síntese racial que o discurso da mestiçagem e da crioulidade propugnavam.

O relevo dado à "cultura", no discurso cabralino, evidencia o reconhecimento do caráter construtivista da nacionalidade, o que comprova as teses de Vale de Almeida e de Gomes dos Anjos, na medida em que a nacionalidade se constitui na cultura que é efeito de uma educação: a cultura, assim, é instrumentalizada, apesar de ser colocada acima de valores nacionais como a tradição, a nacionalidade, etc.

De maneira diversa, o tema do "homem novo" será desenvolvido pelo MPLA em seus documentos históricos posteriores à Independência (1975), enquanto que o conceito de "homem novo" no discurso que constituiu a moçambicanidade aparecera nos estertores da Independência (1975). José Luis Cabaço (CABAÇO, 2009, p. 304) aponta que o "homem novo" moçambicano, apesar de se aproximar de seu semelhante angolano, trazia particularidades oriundas da prática cotidiana da FRELIMO à medida que se desenrolavam as operações bélicas da guerra de independência.

A ausência de políticas eficazes, capazes de mediar as relações dos indivíduos com os modelos tradicionais de identificação e as novas formas projetadas pelo estado nação, é hoje reconhecida como a falha mais evidente para a efetivação mais pacífica do estado nação tanto em Angola, quanto em Moçambique.

A pacificação atingida e a estabilização dos discursos nacionais apenas foram conseguidas após as longas lutas que evoluíram para as guerras civis. Os modelos dos movimentos de libertação foram abandonados e, quando da inserção das economias nacionais na ordem capitalista internacional, um modelo plural de sociedade passou a ser requerido, no caso moçambicano com muito mais possibilidade de sucesso, na medida em que o estado se reorganizou em 1992 a partir de um projeto de nação multicultural (CABAÇO, 2009, p. 323), assim como acontecera em Cabo Verde, anteriormente. A abertura a uma concepção multicultural de nação abriu espaço para a emergência de discursos problematizadores identificados por novos sujeitos que encontravam identificação em marcadores diversos ao da nacionalidade.

O fato de não termos observado, com pormenores, em nossa breve exposição acerca do projeto político do "homem novo", a emancipação feminina nesses espaços nacionais não significa que os estados e as 
sociedades não a tenham promovido. Pelo contrário, o reconhecimento por parte dos estados do protagonismo social feminino vem resultando em ações efetivas, especialmente quando observadas estatisticamente. ${ }^{16}$ Do processo histórico e social que buscamos observar, fica registrada a falência dos projetos centralizadores que se escoravam na ação do estado e que abriam mão da dinâmica social e cultural. A opção pelo multiculturalismo e a consequente abertura dos regimes políticos, além das garantias de liberdade de expressão e manifestação individual, inseriram essas sociedades em contextos internacionais diversos, confrontando-as a questões até então próprias das nações pós-industrializadas e incluídas na chamada pós-modernidade. O salto histórico e temporal foi grande e, ao mesmo tempo perturbador especialmente à identidade masculina, protegida pela manutenção da lógica bélica que animava a masculinidade nos anos de luta pelas independências. É dessa maneira que passamos à observação de algumas obras das literaturas moçambicana, angolana e cabo-verdiana, não sem antes buscarmos, no âmbito literário, a contextualização do problema.

\section{REFERÊNCIAS BIBLIOGRÁFICAS}

ALEXANDRE, Valentim. O império português (1825-1890): ideologia e economia. In: Análise Social, vol. XXXVIII (169), p. 959-979, 2004.

Marialvismo. Fado, touros e saudade como discursos da masculinidade, da hierarquia social e da identidade nacional. In: Trabalhos de Antropologia e Etnologia, v. 37 (1-2), p. 41-66, 1997.

. Outros Destinos: Ensaios de Antropologia e Cidadania. Porto: Campo das Letras. 2004.

. Senhores de si: uma interpretação antropológica da masculinidade. 2. ed. Lisboa: Fim de século, 2000.

AMBRÓSIO, António. Subsídios para a História de S. Tomé e Príncipe. Lisboa: Horizonte, 1984.

ANJOS, José Carlos Gomes dos. Intelectuais, Literaturas e Poder em Cabo Verde: lutas da definição da identidade nacional. Tese (Doutorado em Letras). Porto Alegre: UFRGS, 1998.

ARAGÃO, Rui. Portugal, o desafio nacionalista: psicologia e identidade nacionais. Lisboa: Teorema, 1985.

BENJAMIN, Walter. Magia e técnica, arte e politica (Obras escolhidas, v. 1). São Paulo: Brasiliense, 1987.

BERMAN, Marshall. Tudo que é sólido desmancha no ar: a aventura da modernidade. São Paulo: Companhia das letras, 1987.

BOSWELL, John. Christianity, social tolerance, and homosexuality: gay people in Western Europe from the beginning of the Christian era to the fourteenth century.Chicago: The University Of Chicago Press, 1981. 
CABAÇO, José Luís. Moçambique: identidade, colonialismo e libertação. São Paulo, Editora UNESP, 2009.

CABRAL, Amílcar. Livro. s/l; s/ed; s/d. Disponível em: http://www. amilcarcabral.org. Acesso em 15/07/2011.

CONNELL, R. W. A very straight gay: masculinity, homosexual experience and the dynamics of gender. In: American Sociological Review, (57), p. 735-751, 1992.

CONNEL, R. W. Masculinities. Berkerley: University of California Press, 1995.

EDINI, Gloria. The Top 10 Myths About HIV and AIDS, 2009. Disponível em: http://gloria.taboca.com/artigos/text11.html. Acesso em 18/07/2010.

EKSTEINS, Modris. A sagração da primavera: a grande guerra e o nascimento da era moderna. Rio de Janeiro: Rocco, 1991.

FOUCAULT, Michel. As palavras e as coisas. São Paulo: Martins Fontes, 1990 (1965).

. A ordem do discurso. São Paulo: Loyola, 1998a.

FREYRE, Gilberto. Casa Grande \& Senzala. São Paulo: Circulo do Livro, 1986.

GUIBERNAU, Montserrat. Nacionalismos: o estado nacional e o nacionalismo no século XX. Rio de Janeiro: Jorge Zahar, 1997.

GUIMARÃES, Ângela. A ideologia colonialista em Portugal no último quartel do sécu1o XIX. In: Ler História (1), 1983: 69-79.

Uma corrente do colonialismo português., Lisboa: Horizonte, 1984.

JESUS, Diego Santos Vieira de. Bravos novos mundos: uma leitura pós-colonialista sobre masculinidades ocidentais. Revista Estudos Feministas. v. 19, n. 1, p. 125-140, 2011.

KOLBANOSKI, V. “A Moral Comunista (1947)”. In: Problemas - Revista Mensal de Cultura Política, 17, fev-mar. In: Marxist Internet Archive. Disponível em: http://www.marxists.org/portugues/tematica/rev_prob/17/ moral.htm. Acesso em 18/07/2011.

LUGARINHO, Mário César. Manuel Alegre: mito, memória, utopia. Lisboa: Colibri, Universidade Nova, 2005.

MARIANO, Gabriel. Cultura cabo-verdiana: ensaios. Lisboa: Vega, 1991.

MOSSE, George L. La imagen del hombre: la creación de la moderna masculinidad. Madrid: Talasa Ediciones, 2000. 
MURICY, Katia. A razão cética: Machado de Assis e as questões de seu tempo. São Paulo: Companhia das Letras, 1988.

PORTUGAL. Código Civil Portuguez (1867). 2a Ed. Lisboa: Imprensa Nacional, 1868. Disponível em: http://www.fd.unl.pt/ConteudosAreasDetalhe.asp $? \mathrm{ID}=60$ \&Titulo=Biblioteca\%20Digital \&Area=BibliotecaDigital . Acesso em 05/08/2011.

PORTUGAL. Ministério do Ultramar. Decreto Lei de 18 de novembro de 1869. Extensão do Código Civil Portuguez (1867) ao Ultramar. Lisboa: Imprensa Nacional, 1869. Disponível em: http://www. fd.unl.pt/ConteudosAreasDetalhe.asp? ID=60\&Titulo=Biblioteca $\% 20$ Digital\&Area=BibliotecaDigital. Acesso em 05/08/2011.

PORTUGAL. Ministério do Ultramar. Decreto Lei no 43893, Revogação do Estatuto do Indígena. In: Diário da República (Portugal), 06/09/1961. http://www.dre.pt/cgi/dr1s.exe?t=dr\&cap $=1-1200 \& d o c=19611716 \% 20$ $\& \mathrm{v} 02=\& \mathrm{v} 01=2 \& \mathrm{v} 03=1900-01-01 \& \mathrm{v} 04=3000-12-11=$ 'DecretoLei' \&v12 $=\& v 13=\& v 14=\& v 15=\& s o r t=0 \& s u b m i t=$ Pesquisar. Acesso em 05/08/2011.

RAMOS, Rui. A segunda fundação (1891-1926) [História de Portugal, 6, dir. De José Mattoso]. Lisboa: Estampa, 1994.

RAMOS DO Ó, Jorge. Salazarismo e cultura. In: SERRÃO, J. \& OLIVEIRA MARQUES, A. H. (Orgs.). Portugal e o Estado Novo (19301960) [Nova História de Portugal, XII, coord. Fernando Rosas]. Lisboa: Presença, 1992. p. 391-454.

SANTOS, Maria E.; TORRÃO, Maria Manuel F; SOARES, Maria J. (Orgs). História concisa de Cabo Verde. Lisboa: Instituto de Investigação Científica Tropical, Praia: Instituto da Investigação e do Património Cultural, 2004.

SOUSA, Laura de Mello. O diabo na terra de Santa Cruz. São Paulo: Companhia das Letras, 1986.

THERBORN, Göran. Sexo e poder: a família no mundo 19002000. São Paulo: Contexto, 2006.

TORGAL, Luis Reis. Estado novo, estados novos: ensaios de história política e cultural. 2. ed. Coimbra: Imprensa da Universidade, 2009.

TRONI, Alfredo. Nga Muturi. Prefácio de Mario António. Lisboa: Edições 70, 1973.

VAINFAS, Ronaldo. Trópico dos pecados: moral, sexualidade e Inquisição no Brasil. Rio de Janeiro: Civilização Brasileira, 2010. 


\section{NOTAS}

1 É preciso lembrar que a masculinidade europeia e cristã se constituiu como uma negação da antiga masculinidade romana. Práticas comuns aos homens romanos, como a vaidade e a sodomia, foram eliminadas e, quando exercidas, determinavam a perda dos atributos da masculinidade, tornando o indivíduo menos homem e lançando-o à subalternização ou excluindo-o do exercício das práticas de poder usualmente exercidas por outros homens. (BOSWELL, 1981).

2 George Mosse assinala que a relação entre a identidade masculina e suas alteridades, quando da construção dos estados nacionais, atrelava-se também à presença de inimigos externos e internos "aparentemente inclinados a destrucción de la masculinidad" (MOSSE, 2000, p. 68). A guerra fortalecia o estereotipo masculino e os inimigos reforçavam-se como opositores evidentes. Mosse afirma que, no tempo das guerras napoleônicas, franceses e alemães acusavam-se mutuamente de serem exemplos negativos de homens, o que reforçava a autorrepresentação de sua absoluta superioridade masculina ou, melhor, de sua maior aproximação aos estereótipos. Vale assinalar, também, que mais do que o inimigo externo, aqueles que, ocultos no interior das nações e que expressavam uma alteridade evidente, ameaçavam o estereotipo masculino eram considerados, muitas vezes, mais perigosos do que o inimigo externo. Classificá-los, discipliná-los, curá-los ou puni-los era imperioso para que a sociedade burguesa obtivesse uma coerência interna e uma autoimagem vigorosa e íntegra frente aos inimigos externos.

3 A História concisa de Cabo Verde (2007), publicação conjunta do Instituto de Investigação Científica Tropical (Lisboa) e do Instituto da Investigação e do Patrimônio Culturais (Praia), ao narrar o início do povoamento do arquipélago, apresenta uma carta régia datada de 12 de Junho de 1466, em que o rei, ciente da distância e das condições climáticas locais, alicia colonizadores com "mui grandes liberdades e franquezas", entre as quais autorizar os colonizadores a "cada vez que lhes prouver" poderem ir à costa africana abastecerem-se de escravos. O mesmo relato historiográfico, mais adiante, recorre à Noticia corográfica e cronológica do bispado de Cabo Verde, datada de 1784, de autoria anônima, para documentar que o processo de mestiçagem, apesar de esforços do poder local e da metrópole, já era observado desde os primórdios do povoamento do arquipélago. Em São Tomé e Príncipe não seria muito diferente, apesar de a mestiçagem ter-se dado de forma mais imediata, como afirma António Ambrósio em Subsídios para a História de S. Tomé e Príncipe (1984), na medida em que "a cor preta e mulata ficou a ser predominante em S. Tomé logo a partir dos princípios do século XVI (...) o que valeu aos filhos de escravos nascidos em S. Tomé e Príncipe o reconhecimento dos direitos de homens livres" (p. 09-10).

4 As ordenações eram conjuntos de leis, ordens, decretos e normas jurídicas que organizavam tanto o serviço público quanto o Direito e a Justiça do reino português e de seus domínios no Ultramar. As mais antigas são as Ordenações alfonsinas (1446), seguidas pelas Ordenações manuelinas (1521) e substituídas pelas Ordenações filipinas (1603). O Código Civil, de 1867, que substituiu as antigas Ordenações, vigorou até 1966, quando foi substituído por outro, ainda em vigência, apesar das inúmeras modificações desde então.

5 A “ordem de gênero" expressa a forma como as relações de gênero se organizam em hierarquias rígidas que definem previamente a posição ocupada por indivíduos num conjunto social, estabelecendo formas de controle sobre as suas atividades e escolhas. A sua manutenção é garantia de estabilidade social e, comumente, para tanto todos os indivíduos são convocados.

6 A narrativa de Alfredo Troni, Nga Muturi (1881[1973]), ilustra bem a aplicabilidade do Código, já que a protagonista, viúva e sem filhos, herda as propriedades do marido português e passa a geri-las de maneira autônoma, sem que houvesse quaisquer questionamentos por parte da sociedade ou mesmo da administração colonial e de seu aparelho jurídico.

7 A expressão emergiu primeiramente na educação jesuítica, no século XVII, a partir da qual os religiosos, imbuídos da pedagogia humanista, vislumbravam a construção de uma nova sociedade no Novo Mundo.

8 "Portugal, através do Estado, assumia a sua função missionária na História dirigindo-se a uma tarefa civilizadora junto aos povos dominados e perante o concerto das nações. Para que tanto se configurasse, já que a economia teria que dispor diretamente dos terri- 
tórios ultramarinos para a execução do projeto político-econômico de Salazar, era necessário que se dispusesse da mística nacional portuguesa, que por agora se convertia pela institucionalização da 'portugalidade”'. (LUGARINHO, 2005, p. 53 e ss.)

9 O conceito de "regeneração", inicialmente, aludia à religião, como efeito do "renascimento espiritual" a partir do ritual do batismo, mas passou, durante o século XIX, a também indicar as formas de recuperação vital de organismos, tendo sido recorrente no emergente discurso sanitarista daquele século (v. MURICY, 1988). Como já vimos, foi um tema recorrente na cultura portuguesa nos anos que antecederam a República.

10 Modris Eksteins (1991) destaca que a I Grande Guerra fora uma luta entre o idealismo alemão, o liberalismo inglês e o racionalismo francês e que fora vencida pelo capitalismo norte-americano. O confronto seria continuado até o fim da II Grande Guerra, com o triunfo do amálgama entre o liberalismo e o capitalismo, constituindo a forma da democracia liberal, paradigma para os regimes políticos a partir daí, na medida em que valores individuais, como liberdade de expressão e opinião disseminaram-se universalmente através da Carta da Organização das Nações Unidas (1945). Alertamos, além disso, que se deve ter sempre em mente que a ultrapassagem do século XIX para o século XX guarda uma profusão de manifestações culturais, científicas e filosóficas, nenhuma das quais se tornou capaz de silenciar as outras. Pelo contrário, criaram ainda mais a capacidade de serem geradas outras manifestações. Esse processo culmina efetivamente quando se reconhece, já na década de 1960, a importância e a validade das múltiplas interpretações e, principalmente, o caráter de "constructo" dos objetos científicos, da "verdade" científica e da própria vida cotidiana. A morte do homem, como pensara Foucault, em As palavras e as coisas (1965), fez da prática interpretativa o cerne do conhecimento e da ciência contemporâneas.

11 Tanto a medicina legal como a antropologia criminal, do século XIX se detiveram no estudo da fisiognomia e frenologia, dando atenção especial aos tipos marginais à sociedade, não apenas criminosos ou esquizofrênicos, mas também aqueles que apresentavam comportamento desviante, desde a homossexualidade até as mais diversas patologias físicas e/ou psicológicas, estabelecendo uma relação direta entre o caráter e a forma física do indivíduo.

$12 \mathrm{O}$ artigo, retirado da internet, pode ser encontrado em várias traduções e, segundo o site Marxist Internet Archive (http://www.marxists.org/), foi publicado e republicado inúmeras vezes em periódicos e panfletos de vários partidos comunistas internacionais.

13 O revestimento desses elementos ditos "universais" seria retirado da cultura clássica, dominante nas formas de representação da república francesa e do império napoleônico.

14 Fosse com a intervenção no direito consuetudinário das colônias, desde o século XIX, fosse com a publicação do Estatuto Político, Social e Criminal dos Indígenas de Angola e Moçambique, de 1926, fosse com o decreto do Ato Colonial, de 1930, fosse com a publicação da Carta Orgânica do Império Colonial Português e Reforma Administrativa Ultramarina, de 1933 e, finalmente, com o decreto do Estatuto dos Indígenas Portugueses das Províncias da Guiné, Angola e Moçambique, de 1954.

15 Devemos registrar que as observações sobre o conceito de "homem novo" em Cabo Verde, Angola e Moçambique são colhidas a partir de investigações muito mais pormenorizadas do que aquelas apresentadas aqui e cujas referencias se encontram ao longo dos próximos parágrafos.

16 Informações sobre evolução social e educacional, por idade, gênero e região, são fornecidos pela Unesco, in: http://www.unesco.org. 